\section{Dental volunteering - a time for reflection and a time for change}

C. Holmgren ${ }^{1}$ and H. Benzian ${ }^{2}$

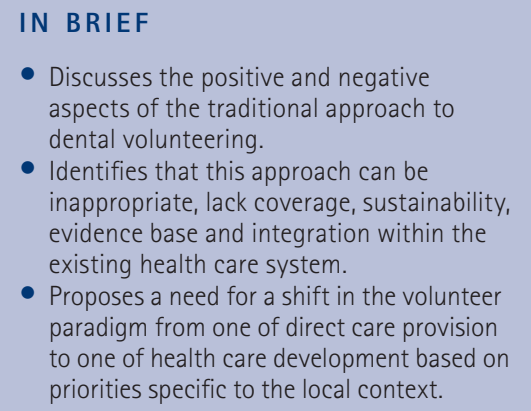

Dental volunteers and their NGOs may have the potential to make a significant and long-lasting contribution to global oral health. However, their traditional approach to volunteering in developing countries can be questioned as to its appropriateness and sustainability combined with potential harmful effects that it might bring to the local health system. This article reviews the positive and negative aspects of this approach to dental volunteering and examines possible changes that could be made to the prevailing volunteer paradigm.

\section{ARE VOLUNTEERS ONLY DOING GOOD?}

A brief perusal through the pages of past issues of the British Dental Journal will reveal that dental volunteering and charity work remain very much current topics in the United Kingdom with requests for dentists to volunteer their services both at home and abroad, to donate their used equipment for use in developing countries or to participate in activities to help fund volunteer organisation projects. Furthermore, over the years, the British Dental Journal has published numerous enthusiastic reports from volunteers and their non-governmental organisations (NGOs) on their experiences in places as far apart as Amazonia and Vietnam.

It is undeniable that there is a need to reduce the enormous global burden of oral disease and its effects on general health and quality of life. ${ }^{1,2}$ Dental decay affects over $90 \%$ of the world's population and in most low- and middle-income countries almost all decay remains untreated

"Aide Odontologique Internationale, Paris, France;

${ }^{2}$ The Health Bureau, Haversham, UK

*Correspondence to: Dr Christopher Holmgren,

Puychevrier, 36220 Merigny, France

Email: globalart@free.fr

\section{Refereed Paper}

Accepted 3 May 2011

DOI: $10.1038 /$ sj.bdj.2011.426

${ }^{\circledR}$ British Dental Journal 2011; 210: 513-516 due to a complex set of reasons; lack of access to affordable oral healthcare being the most significant. ${ }^{3}$ This provides motivation for dentists to volunteer in resource-poor communities to provide dental care.

While volunteering can be a hugely rewarding experience for those who volunteer, as long ago as the 1960s concern was being expressed as to the real benefits to the host community of such actions and that there might be negative effects of volunteer actions in developing countries. ${ }^{4}$ Some authors have even questioned whether NGOs could do more harm than good by their actions. ${ }^{5,6}$ In the dental sector, the traditional model of volunteering focusing on short-term clinical treatment provision has little or no long-term benefit to the host population. ${ }^{7}$ Based on this premise, it has been suggested repeatedly that there is a need to re-orientate dental volunteers and their NGOs to make the outcomes of their actions more effective while minimising any potential dangers to the local infrastructure. ${ }^{5-9}$ Sadly, it appears that, with a few notable exceptions, the traditional model of volunteering goes on largely unabated.

This article thus considers the positive and negative aspects of the traditional approach to dental volunteering and proposes possible changes that could be made to the prevailing volunteer paradigm.

\section{WHAT IS WRONG WITH THE TRADITIONAL APPROACH TO DENTAL VOLUNTEERING?}

\section{Lack of coverage and sustainability}

For the most part dental volunteers will visit a host community for a matter of a few weeks and deliver care where the extraction of teeth for the relief of pain largely predominates. While such action addresses the immediate individual oral health problems for those who receive care, the continuity of care once the volunteers have returned home is usually a major problem. Since the period spent by the volunteers in the host community is limited, the number of people who receive care is relatively low. Therefore, such a model of dental volunteering, predominantly based on direct hands-on dental treatment by volunteers, poses problems of coverage and sustainability and raises a number of ethical questions that remain usually unanswered.

\section{Inappropriateness of volunteer actions}

The first-time volunteer usually has either very limited or no experience of working outside the confines of a fully equipped modern dental clinic, and has been trained for a model of oral healthcare based on expensive equipment and technology. Arriving in a foreign country, the volunteer is confronted with many new challenges including differences in climate, 
societal structure, language, people's expectations and the healthcare system itself. Without prior reflection or guidance, volunteers usually bring with them their concept of oral healthcare that might be totally inappropriate to the host setting. Volunteer activities predominantly focus on clinical care rather than on prevention or advocacy. Here, little reflection is made on whether a dental clinic equipped with a dental chair is really required or appropriate to provide what usually amounts to the provision of basic dental care. Moreover, there is little or no knowledge about alternative methods of sterilisation that can be used when an autoclave is not available, on how to extract teeth with a limited number of instruments, dispose of medical waste in the field, or how to restore teeth using only hand instruments.

\section{Evidence-based volunteer actions}

In view of the limited resources available in low-income countries, any intervention to improve oral health must have a maximal effect. A review of reports from dental volunteers often reveals that some interventions undertaken might not have a clear evidence base or might even be totally inappropriate. Few dental NGOs, especially those from high-income countries, seek scientific advice. ${ }^{10}$ Examples of such ineffective interventions are the focus on oral health education as a basis for prevention, ${ }^{11}$ a once-off application of fluoride varnish, ${ }^{12}$ a once-off scaling and polish, ${ }^{13}$ or the distribution of toothbrushes and toothpaste in communities where such items are not normally affordable. ${ }^{14}$ The situation is further complicated since existing evidence for interventions is mostly built on research conducted in highincome countries under highly controlled conditions. While such evidence might serve as a guide, it may not be applicable to other resource-poor environments. ${ }^{15}$

\section{Lack of accountability of volunteer and NGO actions}

Benzian et $a l .{ }^{10}$ report that there is little accountability within dental volunteer organisations as evidenced by the lack of quality assurance and performance control. Goal setting and the monitoring and evaluation of the outcomes of interventions are only applied by few organisations. Rarely is the planning, implementation and evaluation cycle for oral health programmes in developing countries as outlined by van Palenstein Helderman et al. ${ }^{16}$ been applied to dental volunteer programmes. This means that although much time, effort and resources may be expended in volunteer programmes, the outcomes in terms of improvements in oral health remain equivocal.

\section{Lack of integration and devaluation of the existing local healthcare system and its workers}

In many developing countries the healthcare system is often weak, particularly so in rural areas. ${ }^{17}$ Instead of working to strengthen the local healthcare system, dental NGOs are often disconnected from it with little attempt at integration. This has the potential to promote the development of parallel systems and duplication. Moreover, the services offered by volunteers may be perceived as superior to those provided by the local healthcare system and may be cheaper or even provided for free. This may lead, at best, to a devaluation of the status of the local health worker and system. ${ }^{7,8}$ Worse, it might also lead to direct competition and undermines any local efforts to strengthen the health system.

\section{Creating a dependence on volunteers and their NGOs}

The work within countries by NGOs and the provision of care by volunteers has the potential for communities and countries to rely on outside assistance rather than developing their own effective care systems. ${ }^{18}$

\section{HOW COULD DENTAL VOLUNTEERS AND THEIR NGOs EVOLVE?}

Usually initiated with the best of intentions and leveraging a huge amount of resources and goodwill, dental volunteers and dental NGOs need to accept and embrace a critical review of their existing approaches. While some of the problems of the traditional dental volunteering paradigm have been outlined above there are no doubt others. The first step to evolution is the awareness of these problems and the acceptance that this model has significant limitations, or even has the potential to cause more harm than good. This is undoubtedly the hardest step on the road to evolution of dental volunteers and their NGOs in the process of making the outcomes of their actions more effective and sustainable while minimising

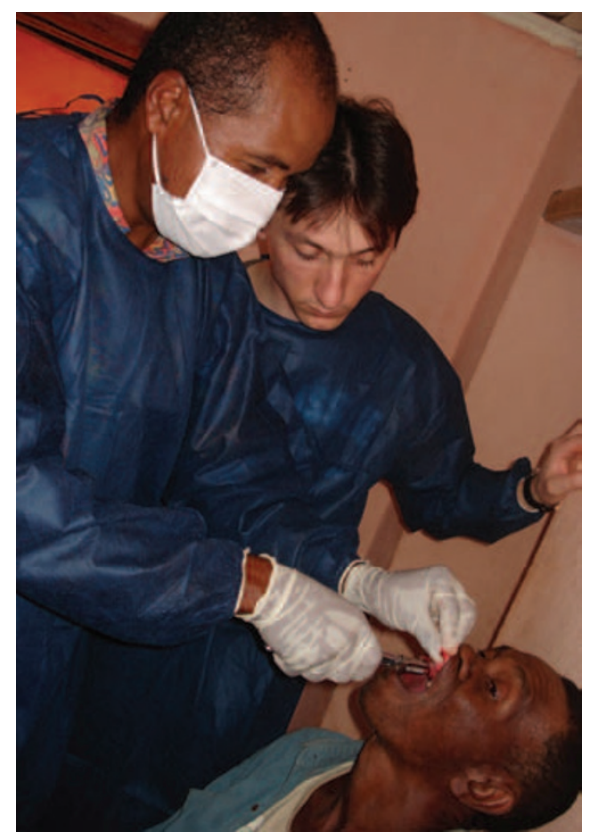

Fig. 1 Rural doctor receiving training in basic oral health care, Madagascar, ๑Aide Odontologique Internationale

the possibility of causing any harm to local health structures.

The concept of the WHO Basic Package of Oral Care (BPOC) ${ }^{19}$ has been proposed as a framework for the evolution of dental NGOs. ${ }^{20}$ The three components of this package are: prevention through the use of affordable fluoride toothpaste (AFT); oral urgent treatment (OUT) for the relief of oral pain, first aid for oral infections and dento-alveolar trauma; and Atraumatic Restorative Treatment (ART) for sealants and restorations. Some ten years have passed since the concept of the BPOC was developed and over this time it has become evident that, where resources are limited, the emphasis should be placed on oral urgent treatment and prevention since ART is likely to be too resource intensive and costly in many situations.

An important and often overlooked aspect of the BPOC is that local non-dental health personnel could deliver much of the basic oral healthcare. This implies that there is a need to develop and strengthen the capacities of such personnel through education and training. The advantages of such a model are that it makes use of existing personnel, it integrates oral health within general health and it has the potential to strengthen the existing local healthcare system. It is, however, essential that such capacity building efforts are coordinated with and recognised by the local system. 


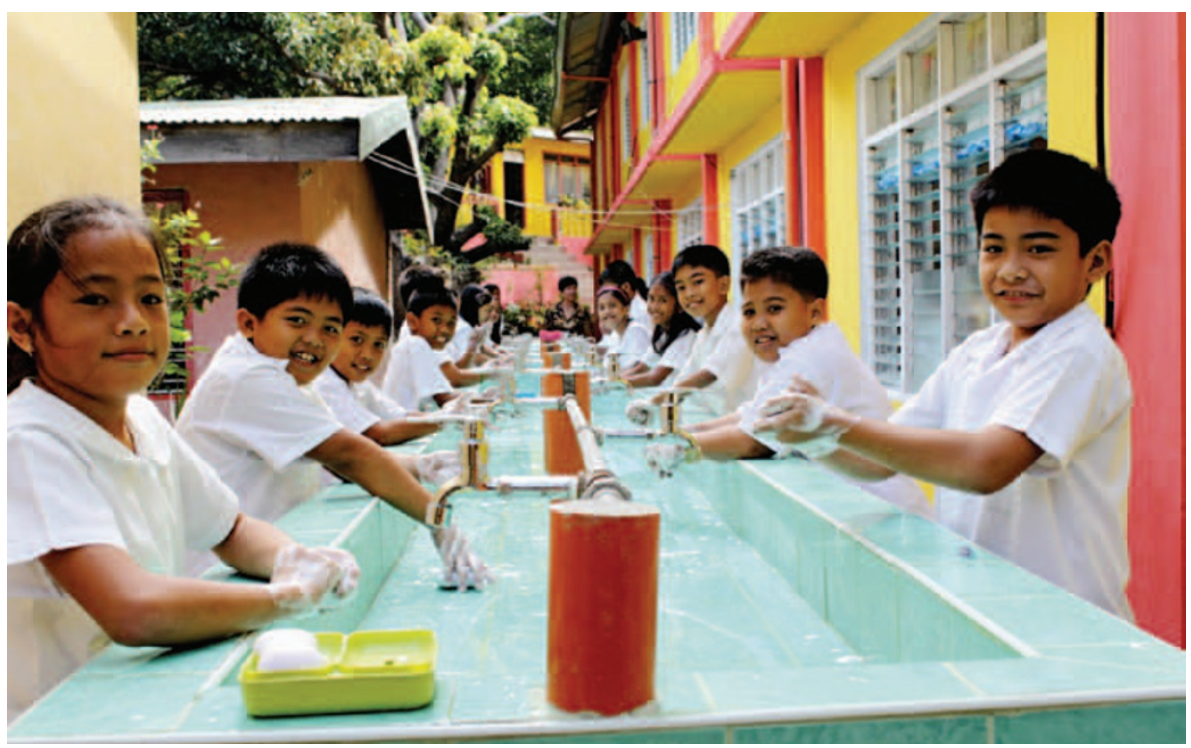

Fig. 2 Children participating in hand washing with soap as part of the Fit for School programme in the Philippines ${ }^{\circ}$ Fit for School/Ivan Sarenas

It is imperative for the NGO to interface with local government to ensure that such action is legally viable. Unfortunately this has not always been the case and, rightly so, the local professional organisations and government agencies need to react strongly to what is considered illegal oral care. ${ }^{21}$ For example, in Rwanda and elsewhere, people were 'trained' by NGOs and given job titles, which afterwards were not formally recognised by the national responsible registration bodies and which created huge problems.

Recently, a small number of dental NGOs has changed their modus operandi towards a capacity development model where volunteers educate local health workers to provide basic oral healthcare (Fig. 1). Although the model of capacity building may seem compelling, the longterm outcomes in the context of dental volunteering are still unknown and require independent and multi-dimensional evaluation. Analysing the findings of such evaluations would help to improve this capacity development model.

Other activities that dental NGOs and volunteers could turn their efforts to include, but are not limited to:

- Advocacy for effective prevention of oral disease. Traditional health education has only limited evidence for long-term behaviour change and knowledge alone does not sustainably improve oral hygiene or personal habits. Advocating for skills-based health education and other evidence-based approaches should become a priority for dental NGOs (Fig. 2)

- Supporting school health with skillsbased oral health promotion. School health programmes offer a very suitable platform for the inclusion of oral health promotion through daily toothbrushing with fluoride toothpaste (Fig. 3). ${ }^{22}$ Dental NGOs can play a significant role in technical assistance, capacity building and advocacy in this context

- Promoting availability and affordability of fluoride toothpaste. The BPOC promotes the use of affordable fluoride toothpaste (AFT) for the prevention of dental caries. Research has shown that in many countries fluoride toothpaste is not affordable for the poorest sectors of the population. ${ }^{14}$ Another worrying aspect is that many so-called fluoride toothpastes, even well known brands, in developing countries do not contain the required levels of free ionisable fluoride to make them effective for caries prevention. ${ }^{23}$ There is therefore an urgent need to work on methods by which fluoride toothpaste can be made more affordable while ensuring adequate quality control to maintain its effectiveness

- Promotion of proper infection control in dental and other health settings (Fig. 4). The capacity development model where local health workers are trained to provide basic oral healthcare, which for the most part will involve

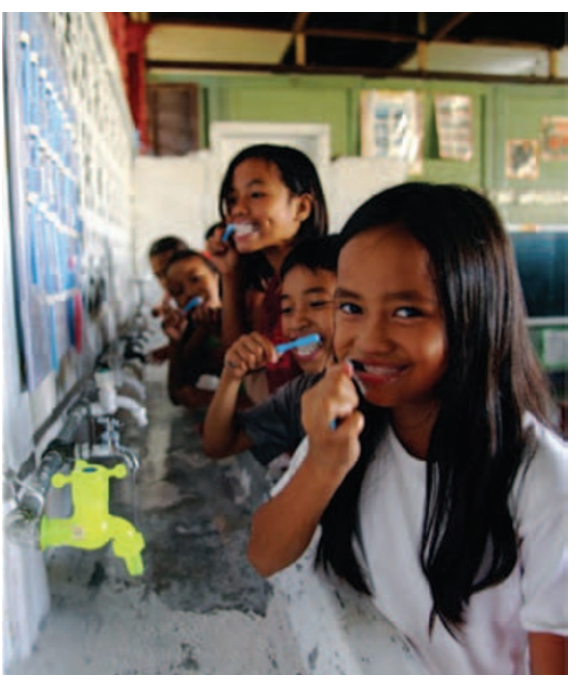

Fig. 3 Children participating in daily toothbrushing with fluoride toothpaste as part of the Fit for School programme in the Philippines ${ }^{\circ}$ Fit for School/lvan Sarenas

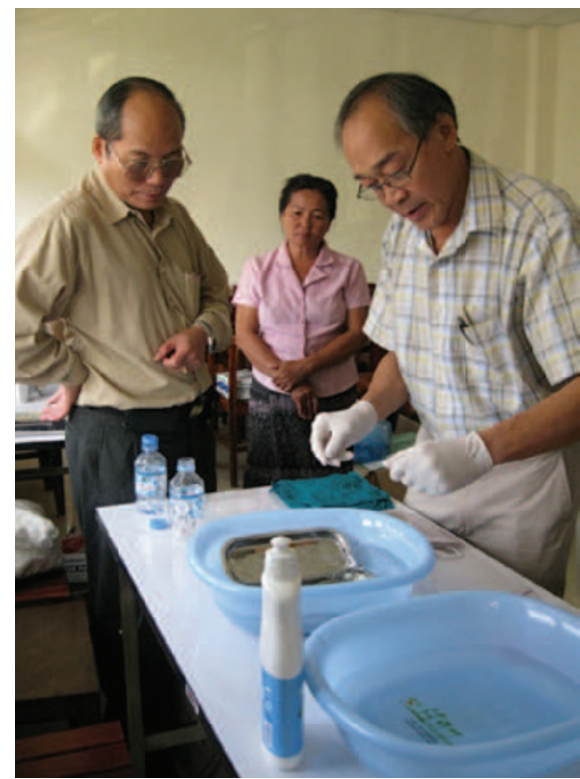

Fig. 4 Rural health care workers being trained in infection control, Laos. ${ }^{\circ}$ Aide Odontologique Internationale

relief of oral pain through extractions, must be based on an assurance that proper infection control methods are consistently and effectively applied.

Evidence suggests that infection control methods practiced by healthcare personnel in developing countries is less than optimal; for instance, the reuse of needles and syringes between patients is commonplace. ${ }^{24,25}$ While there is a paucity of good data on the lack of proper infection control by oral health personnel, some data suggest that needles and anaesthetic cartridges are reused and extraction forceps are not always sterilised between patients. ${ }^{26}$ 
This leads to the concomitant risk of spread of life threatening infections such as HIV and hepatitis. Here a number of NGOs have produced educational material on this subject and organised training but there remains much more to be done on this aspect ${ }^{27}$

- Helping to improve the evidence base on the effectiveness of programmes in developing countries. The evidence base on the efficacy, effectiveness under real-life situations and sustainability of interventions to improve oral health in developing countries remains weak. Dental NGOs working in developing countries have a unique opportunity and obligation to evaluate the outcomes of their interventions. Here there is not only the opportunity to increase the research capacity of local personnel but also to contribute to the wider evidence-based pool of knowledge.

\section{EVOLUTION OF VOLUNTEERING THROUGH REFLECTION, VOLUNTEER TRAINING AND PARTNERSHIPS}

It is clear that the evolution of dental volunteers and their NGOs into new areas of activity means an evolution outside of the traditional dental 'comfort zone' of clinical care. It is essential for volunteers to undergo capacity building themselves in order to make their actions more effective and appropriate. It has been proposed that dental students should follow a course on global oral health to expose them to global public health issues and equip them with more appropriate knowledge beyond clinical approaches that might benefit any future volunteering activities they might pursue. ${ }^{28}$

This having been said, the dental volunteer community as a whole and those working in parallel health sectors in developing countries have a wealth of accumulated years of experience. If it was possible to put vested interest aside, this experience should be collected, analysed and disseminated, which might result in dental volunteering making a more significant and sustained contribution to global oral health. Capitalisation on this wealth of experience could be done both at a national and international level, but needs organisation and funding to become a reality.

With the heavy demands in developing countries from sectors of healthcare for life threatening diseases, for instance, malaria, malnutrition, HIV and tuberculosis, it is not surprising that oral healthcare receives only limited attention. In this respect dental volunteers and NGOs have the potential to support and facilitate the improvement of oral health in these countries. However, in order to develop more appropriate volunteer approaches, there is a need for open dialogue with experts from public health combined with community involvement. It also requires the forging of partnerships, alliances and joint ventures with academia, governments and NGOs from the general health arena.

\section{CONCLUSIONS}

Dental volunteers and their dental NGOs may have the potential to make a significant and long lasting contribution to global oral health but in order to achieve this a shift from the traditional paradigm of direct service provision to one of capacity building for local health personnel and a strengthening of the health structure is required. In the poorest of countries and communities, emphasis must be placed on oral disease prevention and pain relief where possible integrated as part of general healthcare provision. The effectiveness of dental volunteer and NGO action must be enhanced through partnerships with government, professional associations, the university and educational sector, industry and other NGOs.

First and foremost, however, critical reflection about the status quo would be a long overdue start. It should be possible to look beyond the claim of 'doing good' while fully recognising the personal, societal and ethical values of volunteering. To quote a Chinese proverb 'Reflection without action is a dream, action without reflection is a nightmare'.

This article is based on a presentation by Christopher Holmgren on 19 May 2011 in Manchester at the 2011 British Dental Conference and Exhibition Discussion Forum: Volunteering re-visited - is it appropriate to the oral health needs of the developing nations?

1. Petersen P E, Bourgeois D, Ogawa H, Estupinan-Day $S$, Ndiaye $C$. The global burden of oral diseases and risks to oral health. Bull World Health Organ 2005; 83: 661-669.

2. Beaglehole R, Benzian H, Crail J, Mackay J. The oral health atlas: mapping a neglected global health issue. Geneva \& Brighton: FDI World Dental Education Ltd \& Myriad Editions, 2009.

3. Baelum V, van Palenstein Helderman W, Hugoson A Yee $R$, Fejerskov 0 . A global perspective on changes in the burden of caries and periodontitis: implications for dentistry. J Oral Rehabil 2007; 34: 872-906.

4. Illich I. To hell with good intentions. Speech to the Conference on InterAmerican Student Projects
(CIASP), Mexico, April 1968. Available from: http://www.swaraj.org/illich_hell.htm.

5. Bezruchka S. Medical tourism as medical harm to the Third World: why? For whom? Wilderness Environ Med 2000; 77: 77-78.

6. Barber M, Bowie C. How international NGOs could do less harm and more good. Dev Pract 2008; 18: 748-754

7. Benzian $H_{1}$ van Palenstein Helderman W. Dental charity work - does it really help? Br Dent J 2006 201: 413.

8. Dickson M, Dickson G G. Volunteering: beyond an act of charity. J Can Dent Assoc 2005; 71: 865-869.

9. Hardwick K S. Volunteering for the long-term good. Compend Contin Educ Dent 2009; 30: 126-128.

10. Benzian $H_{1}$ Gelbier S. Dental aid organizations: baseline data about their reality today. Int Dent $J$ 2002; 52: 309-14.

11. Kay E J, Locker D. Is dental health education effective? A systematic review of current evidence. Community Dent Oral Epidemiol 1996; 24: 231-235.

12. Chu C H, Lo E C. A review of sodium fluoride varnish. Gen Dent 2006; 54: 247-253.

13. Lembariti $B S$, van der Weijden $G A$, van Palenstein Helderman $\mathrm{W} \mathrm{H}$. The effect of a single scaling with or without oral hygiene instruction on gingival bleeding and calculus formation. J Clin Periodontol 1998; 25: 30-33.

14. Goldman A S, Yee R, Holmgren C J, Benzian H Global affordability of fluoride toothpaste. Global Health 2008; $4: 7$

15. Chinnock P, Siegfried N, Clarke M. Is evidence-based medicine relevant to the developing world? Evid Based Complement Alternat Med 2005; 2: 321-324.

16. van Palenstein Helderman W, Lo E, Holmgren C. Guidance for the planning, implementation and evaluation of oral health care demonstration projects for under-served populations. Int Dent J 2003; 53: 19-25.

17. The International Bank for Reconstruction and Development/The World Bank. World development report 2004: making services work for poor people. New York: Oxford University for the World Bank, 2003.

18. Maclure R. Primary health care and donor dependency: a case study of nongovernment assistance in Burkina Faso. Int J Health Serv 1995; 25: 539-558.

19. Frencken J E, Holmgren $C_{\text {, van }}$ Palenstein Helderman W H. Basic Package of Oral Care (BPOC) Nijmegen, the Netherlands: WHO Collaborating Centre for Oral Health Care, Planning and Future Scenarios, University of Nijmegen, 2002.

20. Helderman W P, Benzian H. Implementation of a Basic Package of Oral Care: towards a reorientation of dental NGOs and their volunteers. Int Dent J 2006; 56: 44-48.

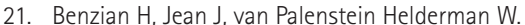
Illegal oral care: more than a legal issue. Int Dent $\rfloor$ 2010; 60: 399-406.

22. Benzian H. Revitalizing school health program worldwide. Compend Contin Educ Dent 2010; 31: 580-582.

23. van Loveren $C$, Moorer W R, Buijs M J, van Palenstein Helderman W H. Total and free fluoride in toothpastes from some non-established market economy countries. Caries Res 2005; 39: 224-230.

24. Simonsen L, Kane A, Lloyd J, Zaffran M, Kane M. Unsafe injections in the developing world and transmission of bloodborne pathogens: a review. Bull World Health Organ 1999; 77: 789-800.

25. Hutin Y J, Hauri A M, Armstrong G L. Use of injections in healthcare settings worldwide, 2000: literature review and regional estimates. BMJ 2003; 327: 1075.

26. Mehtar S, Shisana O, Mosala T, Dunbar R. Infection control practices in public dental care services: findings from one South African Province. J Hosp Infect 2007; 66: 65-70.

27. Organization for Safety, Asepsis and Prevention (OSAP). Guide for safety and infection control for oral healthcare missions. Annapolis, MD: OSAP, 2004. Available from: http://www.osap. org/?ICOralHCMissions.

28. Karim A, Mascarenhas A K, Dharamsi S. A global oral health course: isn't it time? J Dent Educ 2008; 72: 1238-1246. 